\title{
Increased Synaptophysin in the Prefrontal Cortex of Ovarectomized Rats Showing Depressive-like Behavior
}

\author{
Zienab Alrefaie \\ Physiology department, Faculty of Medicine, Cairo University
}

\begin{abstract}
Aim: Synaptophysin is an important synaptic marker. Changes in synaptophysin expression in response to ovarian hormones withdrawal have not been much investigated. The present study aimed to assess the prefrontal cortex (PFC) level of synaptophysin and its possible association with depressive-like behavior in ovarectomized rats. Methods: Twinty female Wistar rats were included into shamoperated control group and ovarectomized group. 16 weeks following the surgical procedures, rats were tested for depression using the forced swim test (FST) and the tail suspension test (TST). Animals were sacrificed under diethyl ether anesthesia and prefrontal cortices were dissected and used for measurement of synaptophysin, brain derived neurotrophic factor (BDNF), nerve growth factor $(N G F)$ and soluble amyloid beta $\left(A \beta^{1-42}\right)$. Results: The present data revealed a significant increase in immobility time in both FST and TST in ovarectomized rats. The PFC of ovarectomized rats exhibited a significant increase in synaptophysin and $A \beta^{1-42}$, while both BDNF and NGF expression showed significant decrease. Conclusion: The present study suggests that the increase in PFC level of synaptophysin could be among mechanisms that underlie the depressive-like behavior demonstrated in ovarectomized rats through enhancement of glutamate release and subsequent glutamate neurotoxicity.
\end{abstract}

Key words: Ovariectomy, depression, synaptophysin, $B D N F, A \beta^{1-42}$

\section{INTRODUCTION}

Depression is estimated by the World Health Organization to be the most important cause of disability in the world by the year $2020^{(\mathbf{1})}$. Not only females are twice as likely to suffer from depression as men, but also their depressive episodes can last longer, be more severe and often recur $^{(2)}$.

About $75 \%$ of women at menopause experience or seek treatment for sleeplessness, anxiety and/or depression. The condition might even reach bipolar and major depression as stated by Weissman and Olfson $^{(3)}$.

Advances have been made in the understanding of signaling pathways underlying the pathophysiology of depression. It was basically thought to be caused by disturbances in the chemical balance of neurotransmitters, namely serotonin and noradrenaline and this was the basis for the monoamine hypothesis of depression $^{(4)}$. Recently, atrophy of dendrites and spines in addition to decreased neurogenesis and synaptic plasticity in the prefrontal cortex and hippocampus are among the postulated hypotheses ${ }^{(5)}$. 
Synaptophysin is one of the most abundant proteins in synaptic vesicles. It functions as a channel in the synaptic vesicle membrane, and it is essential for synaptic vesicle endocytosis, recycling and neurotransmitter release ${ }^{(6)}$. Synaptophysin is also used as a presynaptic marker ${ }^{(7)}$.

Little research has been conducted to investigate the possible role of synaptophysin in the pathophysiology of mood disorders and depression especially in relation to menopause. Most of these researches have been related to the role of hippocampus in depression.

Brains of depressed subjects show structural abnormalities and reduced expression of several markers for neuronal function and viability ${ }^{(8)}$. Neurons and glial cells produce many neurotrophic factors, among which is the brain-derived neurotrophic factor (BDNF). It plays a crucial role in the selection and stabilization of active synaptic contacts ${ }^{(\mathbf{9})}$. Nerve growth factor (NGF), is also an important neurotrophin and both BDNF and NGF have been linked to depression $^{(\mathbf{1 0})}$.

Opposite to neurotrophins which are critical to synaptic plasticity and neurogenesis, brain amyloid-beta peptide 1-42 (A $\left.\beta^{1-42}\right)$ was shown to be related to synaptic dysfunction and decrement in neuronal survival ${ }^{(\mathbf{1 1})}$.

Aim

The present study aimed to assess the possible role of PFC in neurobiology of depression in an experimental model of menopause. PFC levels of synaptophysin, BDNF, NGF and $A \beta^{1-42}$ in addition to their relation to depressive-like behavior were assessed in ovarectomized rats 16 weeks following ovariectomy.

\section{METHODS}

\section{Animals}

20 female Wistar rats (200-250 gram) were used in the present study; they were obtained from animal house, Faculty of Medicine, Cairo University. Rats were maintained on a 12-h light/dark cycle with free access to normal rat chow and water.

\section{Experimental protocol}

Rats were randomly divided into two groups, $n=10$. Group I; control animals, which underwent a sham ovariectomy and Group II; ovarectomized animals. Rats were anesthetized using ketamine (100 $\mathrm{mg} / \mathrm{kg}, \mathrm{im})$. Animals of both groups received no medications throughout the experiment (16 weeks).

Two widely used screening tests were implemented at the end of the experiment to test for depression, the forced swim test, and the tail suspension test. Both tests have good predictive validity and are based on the same principle; measurement of the duration of immobility when rodents are exposed to an inescapable situation $^{(\mathbf{1 2})}$.

Following testing for depression, animals were sacrificed under diethyl ether anesthesia and brains were immediately removed and prefrontal cortices were dissected and kept at -80 until used for measurement of synaptophysin, BDNF, NGF and $A \beta^{1-}$ 42 .

\section{Forced swim test (FST)}

Was conducted according to the traditional method of Porsolt et al. ${ }^{(\mathbf{1 3})}$. The behavioral glass apparatus is 50 
$\mathrm{cm}$ high and $20 \mathrm{~cm}$ in diameter filled with water $\left(25^{\circ} \mathrm{C}\right)$. The water depth is adjusted so that the rat must swim or float without its tail or hind limb touching the bottom. Rats were placed in the cylinder for $6 \mathrm{~min}$. The sessions were videotaped and immobility was recorded during the last 5 minutes; the time during which rat is not making any active movements or very limited movement to keep the head floating. Following the test, animals were dried before being returned to their cages.

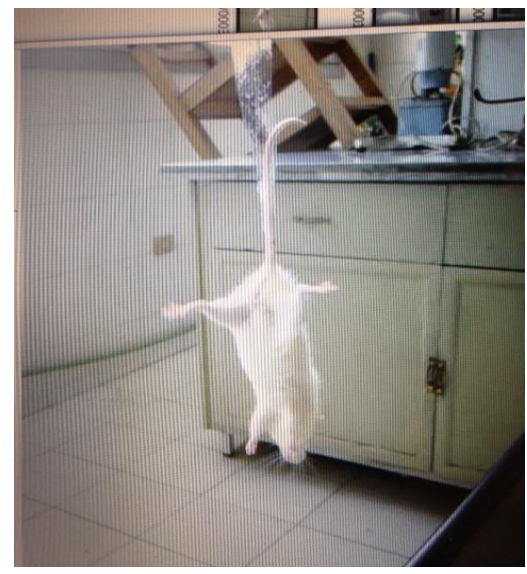

Tail Suspension Test

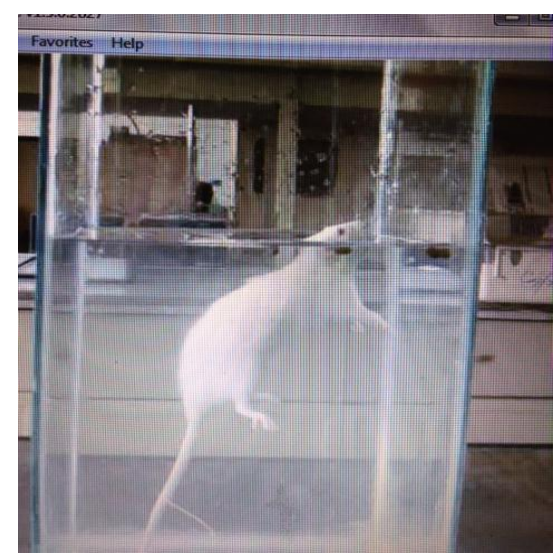

Forced Swim Test

\section{Tail suspension test (TST)}

A short piece of adhesive tape, was attached along the tail with approximately $2 \mathrm{~cm}$ of the tail protruding. The free end of the tape was attached to a $20 \mathrm{~cm}$ long rigid tape which hung from a horizontal bar clamped to a heavy laboratory stand. Each rat was suspended by its tail and observed for $6 \mathrm{~min}$. The sessions were videotaped and immobility was recorded during the last 5 minutes; the duration of passive hanging between periods of wriggling of the animal ${ }^{(14)}$.

Western blot analysis and protein extraction of $\left(\boldsymbol{A} \boldsymbol{\beta}^{1-42}\right)$.

Expression of $A \beta^{1-42}$ in the PFC was determined by western blot analysis. Brain tissue $(50 \mathrm{mg})$ was homogenized using a polytron homogenizer in $1.5 \mathrm{ml}$ cold lysis buffer $(50 \mathrm{mmol} / \mathrm{l}$ Tris-HCL, $\mathrm{pH} 8.0$, $150 \mathrm{mmol} / \mathrm{l} \mathrm{NaCl}, 1 \% \mathrm{NP} 40,0.5 \%$ sodium deoxycholate, $0.1 \%$ SDS and 0.5 $\mathrm{mmol} / \mathrm{l}$

phenylmethylsulfonylfluoride). The homogenate was centrifuged for 20 min at $4{ }^{\circ} \mathrm{C}$ and the supernatant was collected. After boiling at $95{ }^{\circ} \mathrm{C}$ for 5 min, samples $(50 \mu \mathrm{g} /$ lane $)$ were subjected to 7\% SDS-PAGE gel and then transferred to nitrocellulose membranes (Bio-Rad). The membranes were blocked in $7.5 \%$ non-fat dried milk in TBST $(0.05 \%$ Tween-20 Tris-buffered saline) for $2 \mathrm{~h}$ at room temperature and then incubated with primary antibodies overnight at $4{ }^{\circ} \mathrm{C}$; specific antibodies against $\mathrm{AB}^{1-42}$ at 1:1000 (Cell Signaling Technology, Beverly, MA, USA). The membranes were washed and then incubated with a secondary horseradish peroxidase-conjugated anti-rabbit IgG antibody (1:25 000, 
Bio-Rad, Hercules, CA, USA) for $1 \mathrm{~h}$ at room temperature, followed by additional washing. Proteins were visualized by enhanced chemiluminescence (ECL plus; Amersham, Arlington Heights, IL, USA) and $A \beta^{1-42}$ was quantified relative to beta actin using densitometry and Molecular Analyst Software (Bio-Rad, Richmond, CA, USA).

Gene expression of synaptophysin, BDNF and NGF by PCR

RNA was extracted from PFC homogenate using RNeasy Purification Reagent (Qiagen, Valencia, CA). cDNA was generated from $5 \mu \mathrm{g}$ of total RNA extracted with $1 \mu \mathrm{l}(20 \mathrm{pmol})$ antisense primer of each gene and $0.8 \mu \mathrm{l}$ superscript AMV reverse transcriptase for $60 \mathrm{~min}$ at $37^{\circ} \mathrm{C}$. For PCR, $4 \mu \mathrm{l}$ cDNA were incubated with $30.5 \mu \mathrm{l}$ water, $4 \mu \mathrm{l} 25$ $\mathrm{mM} \mathrm{MgCl} 2,1 \mu \mathrm{l}$ dNTPs $(10 \mathrm{mM}), 5$ $\mu l$ 10xPCR buffer, $0.5 \mu l(2.5 \mathrm{U})$ Taq polymerase and $2.5 \mu \mathrm{l}$ of each primer containing 10 pmol. Primer sequences are shown in table 1 . The reaction mixture was subjected to 40 cycles of PCR amplification as follows: denaturation at $95^{\circ} \mathrm{C}$ for $1 \mathrm{~min}$, annealing at $67^{\circ} \mathrm{C}$ for $1 \mathrm{~min}$ and extension at $72^{\circ} \mathrm{C}$ for $2 \mathrm{~min}$. Onetenth of the PCR mixtures was electrophoresed on $2 \%$ agarose gels , stained with ethidium bromide, and visualized by ultraviolet transilluminator. Semiquantitation was performed using gel documentation system (BioDO, Analyser, Biometra, Gottingen, Germany). According to the amplification procedure, relative expression of each studied gene (R) was calculated according to the following formula: densitometrical units of each studied gene/densitometrical units of GAPDH. GAPDH was amplified with the same run of tested genes as housekeeping gene to detect RNA integrity.

The oligonucleotide primers sequence:

\begin{tabular}{|l|l|}
\hline Gene & Primer sequence \\
\hline BDNF & $\begin{array}{l}\text { Forward:5'-ACC CTG AGT TCC ACC AGG TG-3' } \\
\text { Reverse: 5'-TGG GCG CAG CCT TCA T-3' }\end{array}$ \\
\hline NGF & $\begin{array}{l}\text { forward:5'-TGG ACC CAA GCT CAC CTCA-3', } \\
\text { reverse: 5'-GGA TGA GCG CTT GCT CCT-3' }\end{array}$ \\
\hline Synaptophysin & $\begin{array}{l}\text { Forward:5'-TCAGGACTCAACACCTCAGTGG-3' } \\
\text { Reverse:5'- AACACGAACCATAAGTTGCCAA -3' }\end{array}$ \\
\hline GAPDH & $\begin{array}{l}\text { Forward: 5'-TCA CCC TGA AGT ACC CCA TGG AG- 3' } \\
\text { Reverse: 5'-TTG GCC TTG GGG TTC AGG GGG-3' }\end{array}$ \\
\hline
\end{tabular}




\section{Statistical analysis}

Statistical analysis of data was done using SPSS for windows package version 20 (SPSS Inc.,Chicago,IL, USA). Independent T test was used to compare between means of the variables in the control and ovarectomized groups. Results were expressed as mean \pm SD. Pearson's correlation coefficient was used to assess association between variables. A $\mathrm{P}$ value $<0.05$ was considered significant.

\section{RESULTS}

The present data showed significant reduction in serum estrogen level in ovarectomized rats compared to their sham-operated control rats 16 weeks following ovariectomy (Table 1).

\section{Depressive-like behavior}

$\mathrm{T}$ test used for comparing immobility time in both FST and TST revealed that female rats subjected to ovariectomy had developed depressive-like behavior compared to their control rats as indicated by the significant increase in the immobility time in both tests (Table 1).

Table 1: Mean \pm SD of estrogen level and immobilization time in forced swim test (FST) and tail suspension test (TST) in control and ovarectomized rats (T test).

\begin{tabular}{llll}
\hline Parameters & $\begin{array}{l}\text { Estrogen } \\
(\mathbf{p m o l} / \mathbf{L})\end{array}$ & $\begin{array}{l}\text { FST } \\
\text { sec }\end{array}$ & $\begin{array}{l}\text { TST } \\
\text { Sec }\end{array}$ \\
\hline Sham- operated & 134 & 16.5 & 8 \\
control rats & \pm 53.4 & \pm 2.8 & \pm 3 \\
$(\mathrm{~N}=10)$ & & & \\
Ovarectomized rats & 45.4 & 24.5 & 35.7 \\
$(\mathrm{~N}=10)$ & \pm 12.3 & \pm 3.9 & \pm 12 \\
$\mathrm{P}$ & $<0.001$ & $<0.001$ & $<0.001$ \\
\hline
\end{tabular}

$\begin{array}{lll}\begin{array}{l}\text { Prefrontal cortex levels of } \\ \text { synaptophysin }\end{array} & \begin{array}{l}\text { intact rats; synaptophysin was } \\ \text { significantly up regulated in response }\end{array} \\ \begin{array}{l}\text { Gene } \\ \text { synaptophysin }\end{array} \text { showession a significant } & \text { to bilateral ovariectomy (Table 2 and } \\ \text { difference between } & \text { Figure 1). }\end{array}$


Table 2: Mean \pm SD of PFC levels of synaptophysin, brain derived neurotrophic factor (BDNF), nerve growth factor (NGF) and amyloid protein $\beta\left(A \beta^{1-42}\right)$ in control and ovarectomized rats ( $\mathrm{T}$ test).

\begin{tabular}{lllll}
\hline Parameters & Synaptophysin & BDNF & NGF & $\mathbf{A \beta}^{\mathbf{1 - 4 2}}$ \\
\hline Sham- operated control rats & 0.06 & 0.73 & 1.32 & 0.07 \\
$(\mathrm{~N}=10)$ & \pm 0.03 & \pm 0.13 & \pm 0.24 & \pm 0.05 \\
Ovarectomized rats & 0.32 & 0.3 & 0.36 & 0.31 \\
$(\mathrm{~N}=10)$ & \pm 0.16 & \pm 0.15 & \pm 0.26 & \pm 0.2 \\
$\mathrm{P}$ & $<0.01$ & $<0.001$ & $<0.001$ & $<0.01$ \\
\hline
\end{tabular}

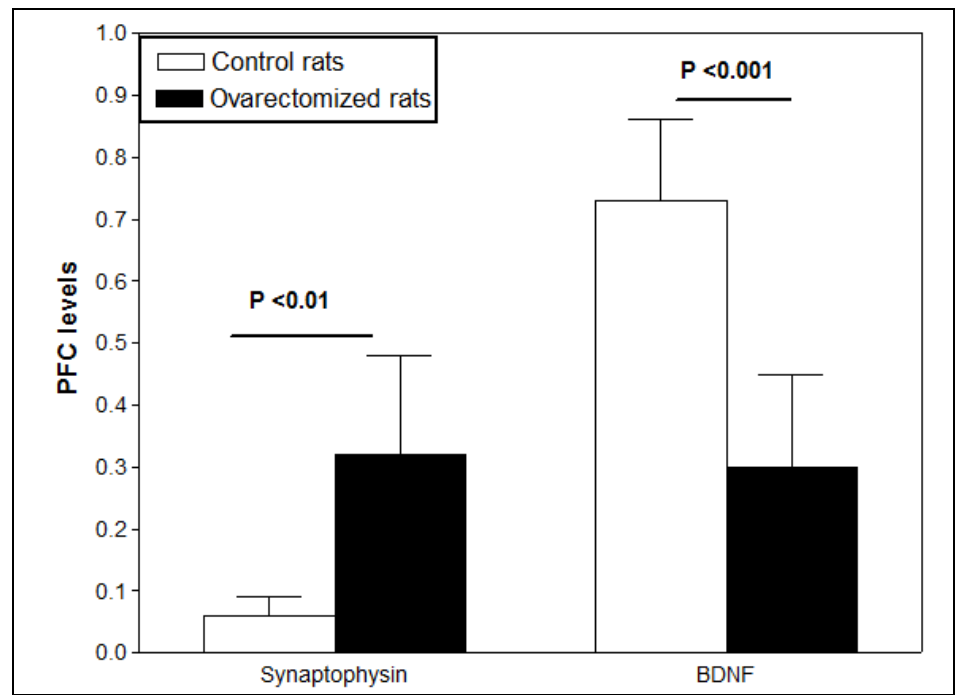

Figure 1: Prefrontal cortex levels of synaptophysin and BDNF in control and ovarectomized rats detected by PCR.

Prefrontal cortex levels of neurotrophins and $A B^{1-42}$

On the other hand, there was significant reduction in the PFC level of BDNF in the ovarectomized group compared to sham operated group. Assessment of NGF revealed the same pattern showing significant reduction in PFC of ovarectomized group. Meanwhile the obtained level of $\mathrm{AB}^{1-}$ 42 was significantly increased compared to control rats (Table 2 and Figure 1,2). 


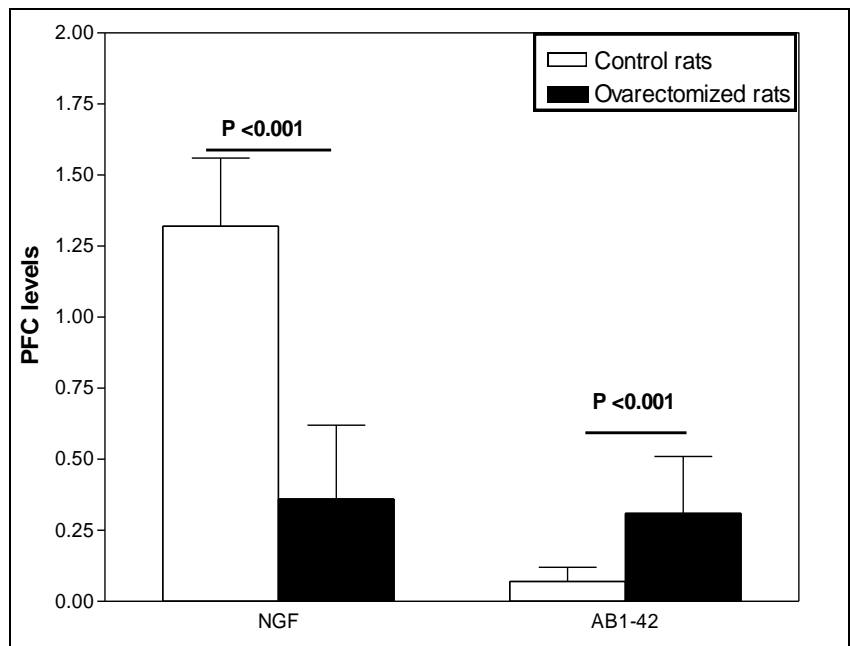

Figure 2: Prefrontal cortex levels of NGF and $A \beta^{1-42}$ in control and ovarectomized rats detected by PCR and Western blot analysis respectively.

\section{Correlation results}

The correlation studies of present work demonstrated a negative significant association between serum estrogen level and immobility time in tail suspension test in ovarectomized group $(\mathrm{r}=-0.727, \mathrm{P}<0.05)$. Otherwise no significant correlations were observed between prefrontal cortex levels of synaptophysin, neurotrophines or $\mathrm{AB}^{1-42}$ and immobility time of the tests used to evaluate depressive-like behavior in ovarectomized group (Figure 3).

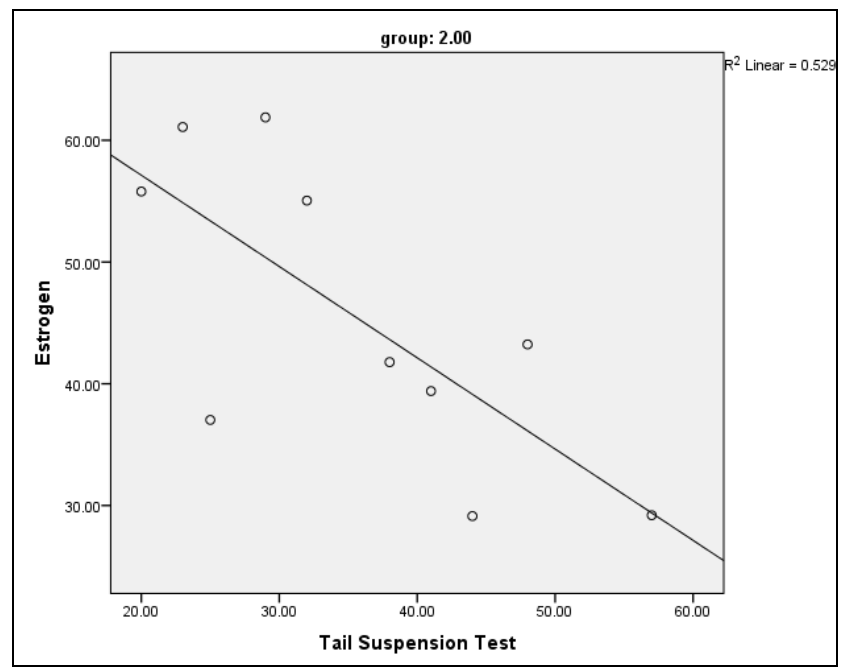

Figure 3: Correlation between serum estrogen level and immobility time in tail suspension test in ovarectomized group. 


\section{DISCUSSION}

The present study revealed depressive-like behavior in female rats, 16 weeks following ovariectomy as indicated by increased immobility time in FST and TST. In agreement with the present finding, higher incidence of anxiety, bipolar and major depression were evident among postmenopausal women ${ }^{(15)}$, and estrogen replacement was shown to improve mode and increases the sense of well-being in postmenopausal women with no or mild depressive symptoms $^{(\mathbf{1 6})}$. Meanwhile the mechanisms underlying depressive behavior in menopausal females are still unsettled.

An emerging important finding in the present study is the significant increase in PFC levels of synaptophysin 16 weeks following ovariectomy.

Little research has been conducted regarding synaptophysin and postmenopausal status.

Velazquez-Zamora et al. ${ }^{(17)}$, observed that estradiole treatment for 3 or 10 days, which started 6 days following ovariectomy, increased synaptophysin expression in hippocampus of ovarectomized rats. Previously, Kretz et al. ${ }^{(\mathbf{1 8})}$, observed upregulation of synaptophysin in hippocampal cell cultures in response to estradiole, but this upregulation was not accompanied by an increase in synaptic button number.

The conflict between synaptophysin findings of the present study and previous works could be referred to the difference in protocol implemented and the tissue examined in previous experiments.

Synaptophysin was found to play an essential role in synaptic vesicles' endocytosis and recycling. It also binds cholesterol and this step is essential for the biogenesis of synaptic microvesicles ${ }^{(\mathbf{1 9})}$. In addition, synaptophysin was shown to be crucial for transmitter release including glutamate and dopamine. ${ }^{(\mathbf{2 0 , 2 1})}$.

Postulating that excess synaptophysin would increase glutamate release, which is known to result in neurotoxicity when not properly regulated at the synapse ${ }^{(\mathbf{2 2})}$, suggests the possibility of glutamatemediated neuronal damage or dysfunction in the PFC of ovarectomized rats.

The term excitotoxicity was originally used by Olney $1969^{(23)}$, to describe the dual actions of glutamate as excitatory transmitter and harbinger of neuronal death.

In support to this postulated hypothesis, is the previous evidence of implications of glutmatergic neurotransmission in severe mood disorders particularly through NMDA receptors leading to neuronal damage $^{(24)}$. Further support to the suggested hypothesis is provided by the observations of Espinosa and Kavalali $^{(25)}$, and Sandi ${ }^{(26)}$, who indicated that during periods of behavioral stress, glutamate accumulates in the extracellular space activating NMDA receptors leading to excitotoxic neuronal damage, also Marsden (27), stated that behavioral stress and depression could reflect hyperglutamatergic state. 
In addition, ketamine, which is NMDA receptor antagonist, produced rapid and sustained antidepressant effect in depressed subjects. Also in experimental models of depression induced in mice, kitamine increased number and function of spines in pyramidal neurons of prefrontal cortex which was associated with antidepressant behavioral responses $^{(28)}$.

The data described in the present work suggest an emerging hypothesis; that withdrawal of ovarian hormones would increase PFC level of synaptophysin with subsequent hyperglutamatergic state which could underlie the behavioral despair observed in ovarectomized rats.

The present work confirms the previous findings regarding role of neurotrophins and $\mathrm{AB}^{1-42}$ in pathophysiology of depression and extends this role to depression associated with menopause.

Present findings demonstrated significant decrease in the PFC levels of BDNF and NGF together with significant increase in $A \beta^{1-42}$ in the ovarectomized rats.

In agreement with the present findings, conditional deletion of BDNF caused depressive behavior in female mice, while central or systemic administration of BDNF produced antidepressant responses ${ }^{(\mathbf{2 9})}$.

BDNF expression was found to be reduced in hippocampus and PFC of postmortem brain of suicide victims $^{(30)}$. In addition, serum BDNF was reduced in depressed subjects and got normalized by antidepressant treatment ${ }^{(31)}$.
Up to our knowledge, PFC level of BDNF has not been previously assessed in ovarectomized rats.

In accord with the present elevation of $A \beta^{1-42}$, higher CSF levels of $A \beta^{1-42}$ were detected in elderly women with major depressive disorder compared to healthy controls $^{(32)}$.

Several mechanisms that explain the association of increased $A \beta^{1-42}$ with behavioral despair include its neuromodulatory action on 5hydroxytryptaminergic and dopaminergic systems in PFC leading to disruption of its function and impairment of mood control as stated by Colaianna et al. ${ }^{(33)}$. The authors showed that intracerebroventricular injection of $A \beta^{1-42}$ also inhibited the expression of BDNF and NGF in PFC of adult male rats and induced a state of despair.

Previous researches showed the effect of ovariectomy on expression of synaptophysin and neurotrophins in the hippocampus which also have been related to depression. The present data regarding the prefrontal cortex contribute to the originality of the present work.

Mechanisms underlying depressive behavior in response to ovarian hormones withdrawal are still unclear. The data presented here highlight some possible alterations in the PFC that could play a role in the pathophysiology of postmenopausal depression. Future studies are required to investigate the postulated role of up regulation of synaptophysin and the possibility of glutamate excitotoxicity as underlying mechanisms. 


\section{CONCLUSION}

The present study revealed an important finding, which is the increased PFC level of synaptophysin in ovarectomized rats 16 weeks following ovariectomy. Increased synaptophysin with possible enhancement in glutamate release and consequent glutamate excitotoxicity could be among mechanisms underlying depressive behavior demonstrated by the increased immobility in the FST and TST. The PFC also showed elevation of $\mathrm{AB}^{1-42}$ together with decreased levels of BDNF and NGF which could also be related to depressive behavior in ovarectomized rats 16 weeks following ovariectomy.

\section{REFERENCES}

1. Murry CJ, Lopez AD. Alternative projections of mortality and disability by cause 1990-2020: global burden of disease study. Lancet 1997;349:1498-1504.

2. Nolen-Hoeksema S. Sex differences in unipolar depression:evidence and theory. Psychol Bull 1987;101:259-282

3. Weissman MM, Olfson M. Depression in women: implications for health care research. Science 1995;269:799801.

4. Castren E. Is mood chemistry? Neuroscience 2005;6:241-246.

5. Shansky R, Morrison JH. Stressinduced dendritic remodeling in the medial prefrontal cortex: effects of circuits, hormones and rest. Brain Res.2009;1293:108113.
6. Daly C, Sugimori M, Moreira JE, Ziff EB, Llinás R. Synaptophysin regulates clathrin-independent endocytosis of synaptic vesicles. Proc Natl Acad Sci 2000; 97(11):6120-5.

7. Evans GJ, Cousin MA. Tyrosine phosphorylation of synaptophysin in synaptic vesicle recycling. Biochem Soc Trans. 2005;33(6):1350-1353.

8. Aan het Rot M, Mathew SJ, Charney DS. Neurobiological mechanisms in major depressive disorder. CMAJ 2009;180: 305313.

9. Greenberg $\mathrm{M} \mathrm{E}, \mathrm{Xu} \mathrm{B}, \mathrm{Lu} \mathrm{B}$, Hempstead BL. New insights in the biology of BDNF synthesis and release: implications in CNS function. J Neurosci 2009;29(41): 12764-12767.

10. Schulte-Herbruggen $O$, Hellweg R, Chourbaji S, Ridder S, Brandwein C, Gass P. Defferential regulation of neurotrophins and serotonergic function in mice with genetically reduced glucocorticoid receptor expression. Exp Neurol 2007;204:307-316.

11. Rowan MJ, Klyubin I, Wang Q, Anwyl R. Synaptic plasticity disruption by amyloid beta protein:modulation by potential Alzheimer'sdisease modifying therapies. Biochem Soc Trans 2005;33:563-567.

12. Castagné $V$, Moser $P$, Roux $S$, Porsolt RD. Rodent models of depression: forced swim and tail suspension behavioral despair tests in rats and mice. Curr Protoc Neurosci. 2011; Chapter 8:Unit 8.10A. doi: 10.1002/0471142301 
13. Porsolt RD, Anton G, Blavet N, Jalfre M. Behavioural despair in rats: a new model sensitive to antidepressant treatments. Eur J Pharmacol. 1978;47: 379-391.

14. Steru L, Chermat R, Thierry B, Simon P. The tail suspension test: A new method for screening antidepressants in mice. Psychopharmacology 1985; 85, 367-70.

15. Wittchen HU, Hoyer J. Generalized anxiety disorder: nature and course. J Clin Psychiatr 2001;62:15-19.

16. Derman RJ, Dawood MY, Stone S. Quality of life during sequential hormone replacement therapy. Int $\mathrm{J}$ Fertil Menopaus Stud 1995;40:73-78.

17. Velazquez-Zamora DA, Gonzalez-Tapia D, GonzalezRamirez MM, Flores-Soto ME, Vazquez-Valls E, Cervantes M. Plastic changes in dendritic spines of hippocampal CA1 pyramidal neurons from ovarectomized rats after estradiol treatment. Brain Research 2012;1470:1-10.

18. Kretz O, Fester L, Wehrenberg U, Zhou L, Brauckmann S, Zhao S, Prrange-Kiel J, Naumann T, Jarry H, Frotscher M. Hippocampal synapses depend on hippocampal estrogen synthesis. J Neurosci 2004;24(26):5913-5921.

19. Thiele $C$, Hannah MJ, Fahrenholz F, Huttner WB. Cholesterol binds to synaptophysin and is required for biogenesis of synaptic vesicles. Nat Cell Biol 2000;2:4249.

20. Shibaguchi H, Takemura K, Kan S, Kataoka Y, Kaibara M, Saito
N, Taniyama K. Role of synaptophysin in exocytotic release of dopamine from Xenopus oocytes injected with rat brain mRNA. Cell Mol Neurobiol. 2000;20(3):401-8.

21. Alder $\mathrm{J}, \mathrm{Lu} \mathrm{B}$, Valtorta F, Greengard P, Poo MM. Calciumdependent transmitter secretion reconstituted in Xenopus oocytes: requirement for synaptophysin. Science 1992;257(5070):657-61

22. Cisneros IE, Ghorpade A. HIV-1, methamphetamine and astrocyte glutamate regulation: combined excitotoxic implications for neuro-AIDS. Curr HIV Res 2012; 10 (5):392-406.

23. Olney JW. Brain lesions, obesity and other disturbances in mice treated with monosodium glutamate. Science 1969;164:719-721.

24. Szakacs R, Janka Z, Kalman J. The "blue" side of glutamatergic neurotransmission: NMDA receptor antagonists as possible novel therapeutics for major depression.

Neuropsychopharmacol Hung 2012;14 (1):29-40.

25. Espinosa F, Kavalali ET. NMDA receptor activation by spontaneous glutamatergic neurotransmission. $\mathrm{J}$

Neurophysiol 2009;101: 22902296.

26. Sandi C. Glucocorticoids act on glutamatergic pathways to affect memory process. Trends Neurosci 2011;34:165-176.

27. Marsden WN. Stressor-induced NMDAR dysfunction as a unifying hypothesis for the etiology, pathogenesis and 
comorbidity of clinical depression. Med Hypotheses 2011;77:508-528.

28. Li N, Liu RJ, Dwyer JM, Banasr $\mathrm{M}$, Lee $\mathrm{B}$, Son $\mathrm{H}$, Li $\mathrm{XY}$, Aghajanian G, Duman RS. Glutamate N-methyl-D-aspartate receptor antagonists rapidly reverse behavioral and synaptic deficits caused by chronic stress exposure. Biol Psychiatry 2011;69:754-761.

29. Autry A, Adachi M, Cheng $P$, Monteggia LM. Gender specific impact of brain derived neurotrophic factorsignaling on stress-induced depression-like behavior. Biol Psychiatry 2009;66:84-90.

30. Dwivedi Y, Rizavi HS, Conley RR, Roberts RC, Tamminga CA, Pandey GN. Altered gene expression of brain derived neurotrophic factor and receptor tyrosine kinase B in postmortem brain of suicide subjects. Arch Gen Psychiatry 2003;60:804-815.

31. Sen S, Duman R, Sanacora G. Serum brain derived neurotrophic factor, depression and antidepressant medication: metaanalyses and implications. Biol Psychiatry 2008;64:527-532.

32. Gudmundsson $P$, Skoog I, Waren $\mathrm{M}$, Blennow $\mathrm{K}$, Palsson $\mathrm{S}$, Rosengren L. The relationship between cerebrospinal fluid biomarkers and depression in elderly women. Am J Geriatr Psychiatry 2007;15:832-838.

33. Colaianna $M$, Tucci $P$, Zotti $M$, Morgese MG, Schiavone S, Govoni S, Cuomo V, Trabace L. Soluble B amyloid 1-42: a critical player in producing behavioral and biochemical changes evoking depressive-related state? $\mathrm{Br} \mathbf{J}$ Pharmacol 2010;159:1704-1715.

\section{المستخلص العربى - (المى}

الهدف: هذه الدراسة تهدف الى تقييم قشرة الفص الامامى للمخ من حيث مستوى سينابتوفيزين

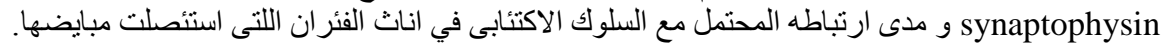

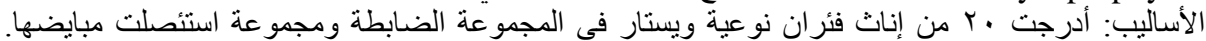

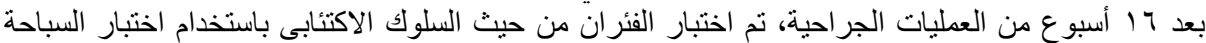

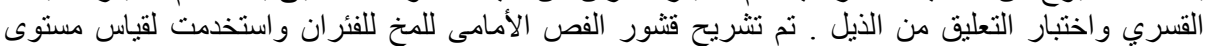

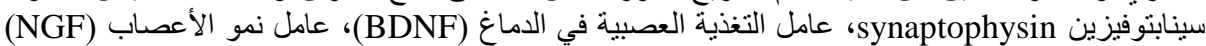

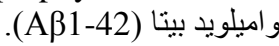

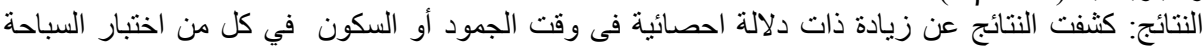

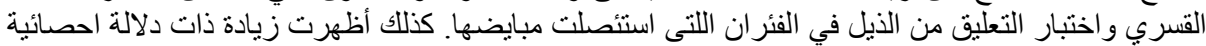

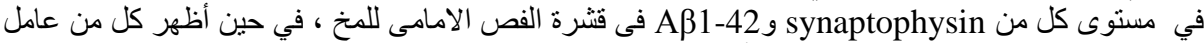

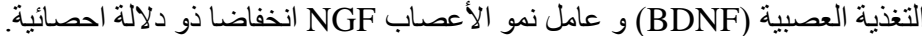

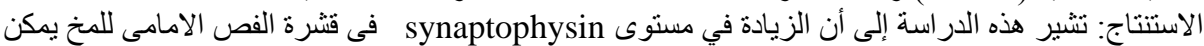
أن يكون من بين الآليات التي تكمن ور اء السلوك الاكتئئابى في الفئران اللتى استئصلت مبايضها 